\title{
多光子記録回折素子を用いた超高速光波位相補償と増幅
}

\author{
西岡一 \\ 電気通信大学レーザー新世代研究センター（†182-8585 東京都調布市調布ヶ 丘1-5-1）
}

\section{All-Optical Ultrafast Phase-Compensation and Amplification by A Multi-Photon-Arranged Diffractive Optics}

\author{
Hajime NISHIOKA \\ Institute for Laser Science, the University of Electro-Communications, 1-5-1 Chofugaoka, Chofu, Tokyo 182-8585
}

(Received April 6, 2009)

\begin{abstract}
This lecture highlights a frequency-domain phase-conjugation (FDPC) device based on multi-photonarranged diffractive optics. The time-reversed replica (i.e. FDPC wave) of an ultrafast pulse train is regenerated by the index grating written by phase-sensitive multi-photon interference. Few-cycle pulse amplification as the coherent superposition of a chirped pump pulse on to a transform-limited seed pulse has been demonstrated.
\end{abstract}

Key Words: Frequency-domain phase conjugation, Time-reversed replica, Photo-refractive, Diffractive optics

1. はじめに

回折光学素子には回折格子, ホログラフィー, あるい は，回折光学レンズ ${ }^{1)}$ な゙，多くの種類がある。これら の素子は, 光波に空間変調を与え, その方向を制御した り記録したりする役割を担っている。

ここでは, 光パルス電場位相の時間形状をそのまま回 折格子として記録する方法について紹介する. 光電場波 形を回折格子として記録すると光電場のフーリエ位相を 記録・演算でき，周波数位相共役波による群遅延分散の 全光学的自動補償やコヒーレンス合成による数サイクル パルス光の増幅が可能になる。

\section{2. 位相敏感 2 光子電場記録と時間反転再生 ${ }^{2)}$}

ホログラフィー ${ }^{3)}$ として良く知られる空間干渉型記録 法では, Fig. 1 (a)に示すように参照ビームと物体から の被記録ビームとの干渉縞を記録している。記録された 干渉縞は, 参照光と物体光との間の角度情報に相当する 空間周波数と，物体の凹凸に相当する(空間周波数の) フーリエ位相を含んでいる4)，読み出しビームを照射す ると記録された空間周波数情報は, 再び角度情報となっ

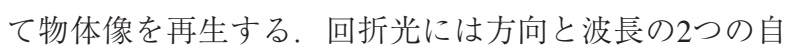
由度があるが，ホログラフィーでは波長を固定してその 方向を再現する。一方，本方法ではFig. 1 (b) に示すよ うに, 時間変調された電場をゲート光と多光子干渉させ
その干渉縞を記録する，別の言い方をすれば，電場角周 波数フーリエ成分を格子の空間周波数フーリエ成分とし て記録する。読み出しパルスを照射すると，記録された 時間情報は時間反転して再生される。この方法では, ビームの方向を固定して光波の時間位相(周波数)を再現 している.

両者は一見，相似に見えるが，本質は物理的記録方法 の違いにある。ホログラフィーが時間積分型(エネル ギー型)の記録素子を用いるに対して，本方法は多光子 吸収による屈折率変化など，強度依存型の物理機構を用

(a) Holography Time integrated energy recording

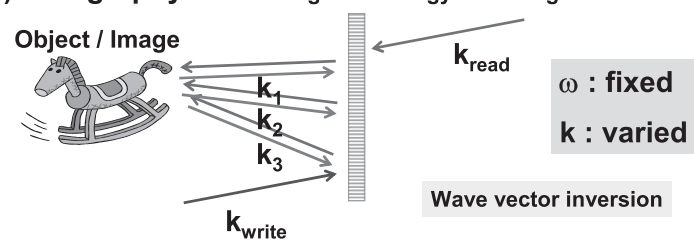

(b) TORPEDO Intensity dependent recording (Two-photon gating) Signal $\omega(t) /$
Time reversed replica
rime reversed
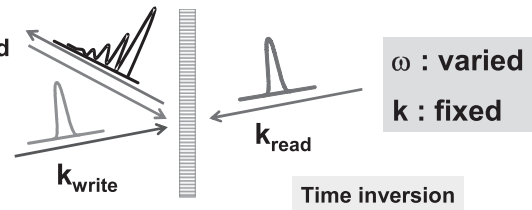

Fig. 1 Comparison between (a) Holography and (b) TORPEDO (see Fig. 2 for detail). The holography and the TORPEDO regenerate wave-vector and pulse shape, respectively. 


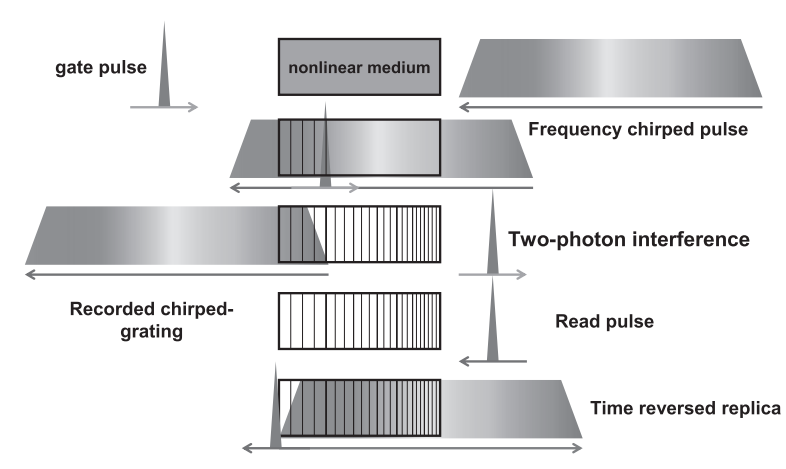

Fig. 2 Phase-sensitive two-photon gated recording and time-reversed playback by TORPEDO. ${ }^{2)}$

いて瞬時電場位相の抽出・記録を実現している.

実際の記録再生の手順をもう少し詳しくFig. 2に示し た。図では分かり易いように正のチャープ光を記録する 様子を示してある. 信号光 (チャープ光) は多光子吸収材 料中でゲート光と時間を追って多光子干渉を起こす。干 渉縞は屈折率変調として記録される. ここで, ゲート光 は信号光とスペクトル帯域の等しいパルスである。単純 にゲート光としてフーリエ限界パルスを用い，信号光と してチャープ光を記録すれば, 干渉縞も同一のチャープ 構造になる。記録された位相情報は，読み出しパルス (ゲート光と同一形状のパルス)を照射する事により，時 間反転して読み出される。一方, 読み出しパルスに記録 された信号光を用いると, 信号光の位相ひずみは相殺さ れフーリエ限界パルス(厳密には書き込みに用いたゲー トパルス)が出力される。時間を追って記録・再生が行 われることから本デバイスを(Time-Ordered Recording/ Readout PEriodic Diffractive Optics: TORPEDO)と呼んで いる.

位相共役波の種類とその物理原理をTable 1にまとめ た。再生される時間反転波は, フーリエ成分の位相 (フーリエ位相)が共役となっているため, 周波数位相共 役波 ${ }^{5)}$ と呼ばれる . 周波数位相共役波を用いると, 群遅
延分散によるパルスひずみを全光学的に自動補償するこ とが可能である。例えば，分散媒質による正チャープし たパルスを時間反転させれば負チャープとなる。これが 再び同じ分散媒質を伝播すれば初期の位相を再生する2).

周波数位相共役波発生法として周波数領域干涉型記録 法「光エコー」が知られるが，その時間分解能・記録時間 幅は記録吸収媒質の不均一幅・均一幅に相当する。記録 材料によって使用できる時間領域に制限が生ずる。たと えば，ナノ秒パルスの記録再生 ${ }^{6}$ には希土類を添加した 結晶などが液体へリウム温度で用いられる。サブピコ秒 領域では，半導体量子ドット7)も盛んに研究されている が，その記録波長やデコヒーレンスにより記憶保持時間 が数ナノ秒に制限されるなどの課題がある.

本原理は光波のフーリエ位相を格子のフーリエ位相と して記録するので任意波形の光パルスを記録・再生でき る。記録できるパルス幅の最小值は原理的にはモノサイ クル，実際には記録媒質の多光子吸収帯域で制限され る。パルス幅の上限は記録媒質中における光伝搬時間の 2倍である。本方法は光エコーと同じ機能を持ちながら， 記録保持時間は半永久で, $100 \mathrm{THz}$ 超える帯域を実現 できる利点がある。

読み出しはどうであろうか．記録される干渉縞の周期 数は光電場と等しい. 回折光は単純な光電場の重ね合わ せであるから, その光強度はコヒーレントな格子数の2 乗に比例する。 回折効率 $\eta_{\text {diffraction }}$ は屈折率変調を $\Delta n$, 格 子のコヒーレンス長 (周期数) を $N_{\text {coherent }}$ として

$$
\eta_{\text {diffraction }} \propto\left(\Delta n N_{\text {coherent }}\right)^{2}
$$

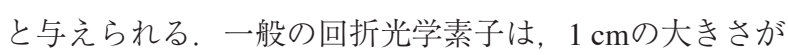
あれば $10^{4}$ 程度の周期数を持つが, 本方法では記録され るパルスが数サイクルパルスならば，その数は 1 桁以下 である、概算でも回折効率は $10^{-6} に$ 低下する。実用的な 回折効率を得るには屈折率変調を3桁大きくする $(\Delta n>0.01)$ 必要がある. DVD-R等に用いられる有機色

Table 1 Phase-conjugation mirrors and their physical principles.

\begin{tabular}{cccc}
\hline Domain & Conjugate parameter & Inversive parameter & System and applications \\
\hline $\begin{array}{c}\text { Space } \\
\mathbf{r}\end{array}$ & $\begin{array}{c}\text { Gradient of wave front: } \varphi(r) \\
\text { (Spatial phase) }\end{array}$ & $\begin{array}{c}\text { Wave vector } \\
\text { (direction) }\end{array}$ & $\begin{array}{c}\text { Fresnel holography } \\
\text { (wave front correction) }\end{array}$ \\
\hline $\begin{array}{c}\text { Spatial } \\
\text { frequency } \\
\mathbf{K}\end{array}$ & $\begin{array}{c}\text { Spherical phase shift: } \varphi(k) \\
\text { (Spatial Fourier phase) }\end{array}$ & $\begin{array}{c}\text { Position } \\
\text { (mirror image or } \\
\text { perspective) }\end{array}$ & $\begin{array}{c}\text { Fourier holography } \\
\text { (aberration correction) }\end{array}$ \\
\hline Time & Instantaneous phase: $\varphi(t)$ & $\begin{array}{c}\text { Spectra } \\
\text { (spectral mirror } \\
\text { placed at degenerate } \\
\text { frequency) }\end{array}$ & $\begin{array}{c}\text { Optical parametric } \\
\text { amplifier }\end{array}$ \\
(Doppler correction) \\
\hline $\begin{array}{c}\text { Angular } \\
\text { frequency }\end{array}$ & Fourier phase: $\varphi(\omega)$ & $\begin{array}{c}\text { Time } \\
\text { (time-reversed } \\
\text { replica) }\end{array}$ & $\begin{array}{c}\text { Photon echo } \\
\text { (GDD correction) }\end{array}$ \\
\hline
\end{tabular}

\footnotetext{
†空間位相共役波を時間反転波と記述している文献を多く見かけるが，これらは誤解である。フーリエ関係から空間位相共役は波動 ベクトル反転であり，時間反転では無い.
} 


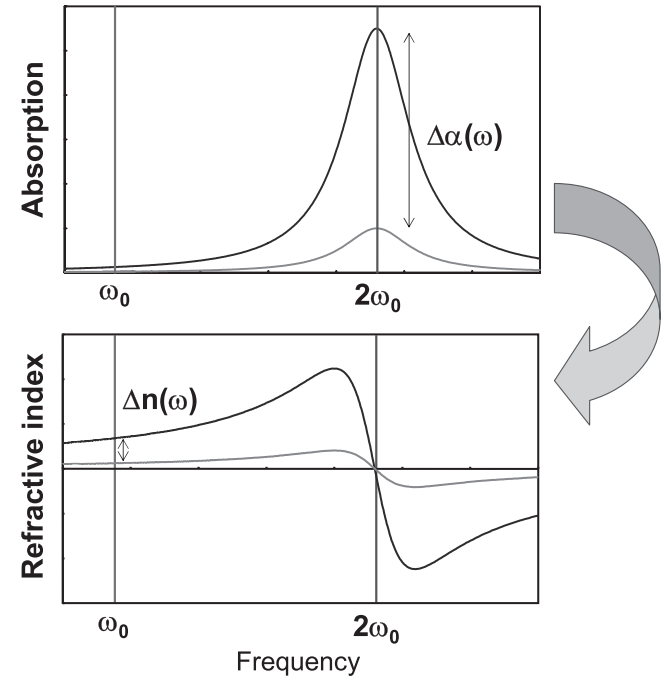

Fig. 3 Index modulation $\Delta n\left(\omega_{0}\right)$ due to two-photon absorption bleaching $\Delta \alpha\left(2 \omega_{0}\right) . \omega_{0}$ : laser frequency.

素やフォトリフラクティブ材料などがこの要求を満たす.

Fig. 3に示すように紫外域に大きな吸収を持つ材料を 用い，2光子吸収によりこの吸収を透明化させる．分散 関係から，基本波波長において吸収変化に応じた大きな 屈折率変化が得られる。

\section{3. コヒーレントビーム合成による 超短パルス光の増幅 8,9}

2本のビームをFig. 4のようにビームスプリッター上で 重ね合わせる時, 境界条件を満たすと入射ビームは完全

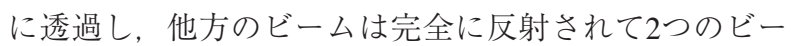
ムは 1 本に合成される，見方を変えると，入射ビームは 形を変えずに2倍の光強度となって出力されており, 光 励起コヒーレント光増幅器として動作していることも分 かる。合成の境界条件は, 他方の透過電場強度が入射電 場強度と等しく逆位相である時である。縦横ともにシン グルモードの連続波レーザー光では境界条件を満たすこ とは比較的容易であるが, 数サイクルの光パルスでは, 時刻(群遅延) と時間的な位相変化(群遅延分散)を含めて 位相を同期させる必要がある。

2光子形成回折素子を用いたコヒーレントビーム合成 の概念図をFig. 5 に示す。励起光と超短パルスの種光は,

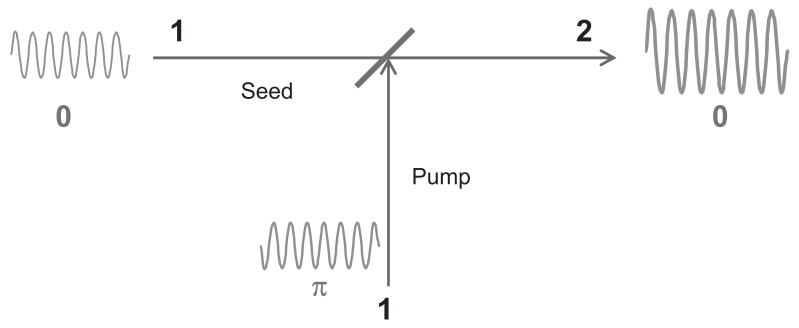

Fig. 4 A coherent beam splitter/combiner: coherent-light amplification based on beam combining. The $\pi$-phase shift is required for the pump to seed energy flow.

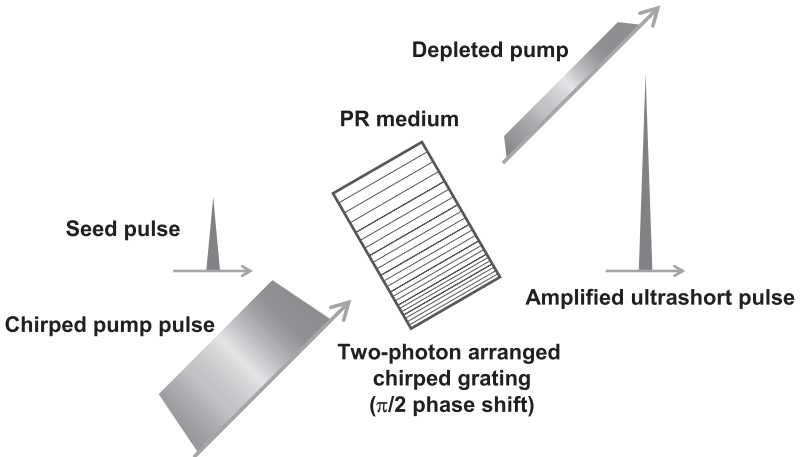

Fig. 5 Schematic illustration of the two-photon arranged photo-refractive amplifier (beam combiner): TAPA. Spatially chirped grating is formed in a PR (photorefractive) medium as a second order cross correlation function between the seed and pump pulses. The first order diffraction of the pump pulse has the same phase structure of the seed. The unidirectional energy flow, the pump to seed, is produced by the $\pi / 2$ grating phase-shift via PR effect.

フォトリフラクティブ材料中で 2 光子干渉を起こし励起 光の位相構造を回折格子として書き达む。吸収により生 じた電荷は拡散し, 空間電荷は干渉縞と $\pi / 2$ の位相シフ トを起こす。このため, ポッケルス効果による屈折率回 折格子は同様に $\pi / 2$ の位相差を持つ ${ }^{10)}$.この格子により ブラッグ回折される光は $\pi$ の位相差を生じ, 上記の境界 条件を自動的に満たす。励起光ビームの時間的位相ひず み(群遅延分散) は内部に形成された周波数位相共役鏡に より補償され, 出力ビームには励起光の位相情報は現れ ない.このため位相ひずみを持つ励起光によってもフー リエ限界パルスの増幅が可能である。

格子形成には2光子吸収を用いるために，記録材料は レーザー基本波に対して透明であり広い増幅帯域を確保 することができる。2光子エネルギー帯にのみ吸収が存 在する理想的な媒質を利用できれば，モノサイクル波の 増幅も可能である。実験ではFe添加ニオブ酸リチウム結

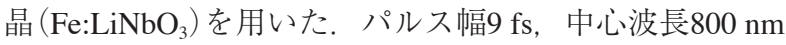
のモード同期チタンサファイヤレーザー光(4サイクル 光）を種光とし, 励起光にはガラスブロックにより伸長 したパルス幅400 fsのチャープ光を用いた. Fig. 6 (a)の ように露光時間と共に空間電荷が蓄積し, 格子が形成さ れる。帯域幅32 THzに渡り増幅が観測され，同時に回 折効率 $27 \%$ を得た。このときスペクトルシアリング干 渉計 ${ }^{11)} に よ り$ 観測したフーリエ位相の時間変化は Fig. 6 (b) に示すように土л/2の範囲であり, 増幅後のパ ルスは初期位相を保存していることが分かる.

\section{4. まとめ}

回折光学素子に瞬時光強度依存型記録を用いることに より光電場の記録，位相補償，増幅に応用できる事を示 した。この非線形記録は, 光メモリ ${ }^{12)}$ や光増幅器に留ま らず，ゲートパルスとして時間波形の助み込みや相関性 抽出など, 全光学システムによる符号化(暗号化), 復号 

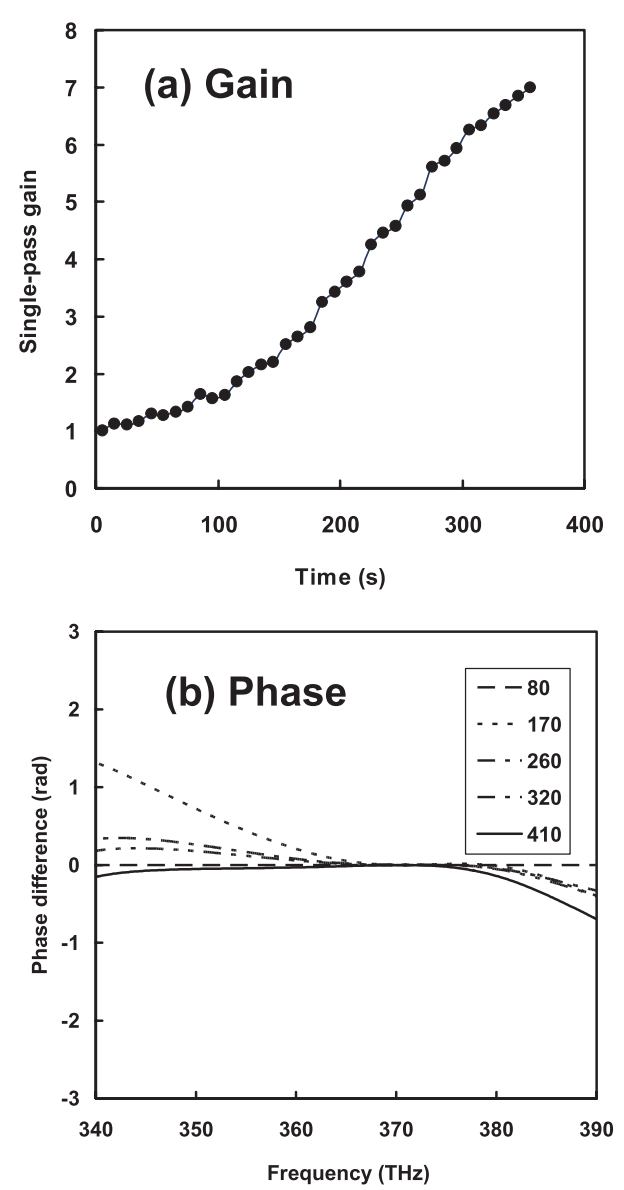

Fig. 6 Gain (a) and Fourier-phase (b) as a function of exposure time. The parameters in (b) are the exposure time in seconds. An intrinsic group-delaydispersion in the medium has been subtracted in this figure. The energy ratio of the pump and seed pulses is $8: 1$.
化を含む超高速コヒーレント信号処理 ${ }^{13)}$ に広く用いるこ とが可能である。本稿は原理の解説に主眼を置き，定量 的な議論や実験の詳細は割愛した。他の原著論文も併せ て参照されたい.

本論文の主な内容は，原著論文として参考文献 ${ }^{2,89}$ に 公表済みである。本研究はその一部を文部科学省「科学 研究費補助金」および「21世紀COEプログラム」の補助を 得て行われた。

\section{参考文献}

1）たとえば「回折光学素子の現状と将来」特集号, レーザー研 究 35 (2007) No. 5.

2) H. Nishioka, H. Tomita, K. Hayakawa, and K. Ueda: Opt. Express 14 (2006) 7447.

3) D. Gabor: Nature 161 (1948) 777.

4) E. Leith and J. Upatnieks: J. Opt. Soc. Am. 52 (1962) 1123.

5) H. Nishioka, S. Ichihashi, and K. Ueda: Opt. Express 10 (2002) 920.

6) M. Mitsunaga and N. Uesugi: Opt. Lett. 15 (1990) 195.

7) K. Kral, Z. Khas, CY. Lin, and S. H. Lin: Opt. Commun. 180 (2000) 271.

8) H. Nishioka, K. Hayasaka, S. Ohta, H. Tomita, and K. Ueda: Opt. Express 15 (2007) 5018.

9) H. Nishioka, S. Ohta, and H. Tomita: Proc. APLS'08, Nagoya, Rev. Laser Eng. 10 (2008) Suppl. p.1113.

10) I. McMichael and P. Yeh: Opt. Lett. 12 (1987) 48.

11) H. Nishioka and H. Tomita: Conference on Laser and Electro-Optics (CLEO), Baltimore, May 31-June 5, 2009, paper CWB3.

12) T. W. Mossberg: Opt. Lett. 7 (1982) 77.

13）たとえば「コヒーレント光通信技術の最新動向」特集号, レーザー研究 37 (2009) No. 3.
フォトリフラクティブ効果 (photo-refractive effect)

光を照射することにより局所的に屈折率変化が生ずる 現象で，発見当初は“Optical Damage”と呼ばれていた。 不純物や欠陷を含む材料に光を照射すると, 不純物が光 吸収を起こしてイオン化し, 生じた電子は伝導带に励起 される。この電子群は密度勾配により拡散・移動を起こ した後，周辺の不純物に捕捉される。こうして，光明部 では正の電荷，その周囲の暗部では相対的に負の電荷が 空間に蓄積されてゆく。この空間電場によってポッケル 又効果 (屈折率変化)を起こす現象である。 その応答は時 間積分型で, 典型的には $1 \mathrm{~W} / \mathrm{cm}^{2}$ の光強度で数十ミリ秒
から秒程度の時間を要する.

2光束間の光干渉により干渉縞を発生させると，縞明 部で発生した電子は隣接する暗部に拡散して，明暗部間 に空間電場が生ずる。したがって，干渉縞の位相と空間 電場は位相差を伴い, 誘起される屈折率変調は光干涉縞 と空間的に $\pi / 2$ の位相差を持つ。この体積屈折率格子に より回折, 反射させる光は $九$ の位相差を持つことにな り，2光束間で光エネルギーの流れ(光増幅)を生ずる.

(西岡一) 